\title{
CSF parameters associated with early MRI activity in patients with MS
}

Ana Klein, MD, Rebecca C. Selter, MD, Alexander Hapfelmeier, PhD, Achim Berthele, MD, Bertram Müller-Myhsok, PhD, Viola Pongratz, MD, Christiane Gasperi, MD, Claus Zimmer, MD, Mark Mühlau, MD, and Bernhard Hemmer, MD

Correspondence Dr. Hemmer

hemmer@tum.de

Neurol Neuroimmunol Neuroinflamm 2019;6:e573. doi:10.1212/NXI.0000000000000573

\section{Abstract}

\section{Objective}

To identify CSF parameters at diagnosis of clinically isolated syndrome (CIS) and MS that are associated with early inflammatory disease activity as measured by standardized cerebral MRI (cMRI).

\section{Methods}

One hundred forty-nine patients with newly diagnosed CIS and MS were included in the retrospective study. cMRI at onset and after 12 months was analyzed for T2 and gadoliniumenhancing lesions. CSF was tested for oligoclonal bands and intrathecal synthesis of immunoglobulin $\mathrm{G}(\operatorname{IgG})$, A ( $\operatorname{IgA}$ ), and $\mathrm{M}$ ( $\operatorname{IgM}$ ) before initiation of disease-modifying therapy (DMT). In a subgroup of patients, CSF and serum samples were analyzed for sCD27, neurofilament light chain, and IgG subclasses 1 and 3. Association between CSF parameters and cMRI activity was investigated by univariable and multivariable regression analysis in all patients, DMT-treated patients, and untreated patients.

\section{Results}

IgG index, sCD27 levels in CSF, and to a lesser extent IgM index were associated with the occurrence of new cMRI lesions. IgG index and sCD27 levels in CSF were highly correlated. In a multivariable analysis, IgG index and to a lesser extent IgM index together with DMT treatment status and gender were strongest predictors of future cMRI activity.

\section{Conclusions}

CSF parameters such as IgG and IgM index are independently associated with future MRI activity and thus might be helpful to support early treatment decisions in patients newly diagnosed with CIS and MS. 


\section{Glossary}

AUC = area under the curve; CIS = clinically isolated syndrome; $\mathbf{c M R I}=$ cerebral MRI; DMT = disease modifying therapy; $\mathbf{N F L}=$ neurofilament $\mathbf{O C B}=$ oligoclonal band; $\mathbf{R O C}=$ receiver operating characteristic; $\mathbf{T E}=$ echo time; $\mathbf{T I}=$ inversion time; $\mathbf{T R}=$ repetition time.

MS is a chronic inflammatory demyelinating disease of the CNS, often leading to accumulation of severe disability over time. In patients presenting with a first clinical manifestation of MS or clinically isolated syndrome (CIS), individual disease course is still unpredictable.

Several cerebral MRI (cMRI) and CSF parameters are associated with early and possibly long-term outcome. A high lesion load on initial cMRI is associated with conversion from CIS to $\mathrm{MS}^{1,2}$ and long-term outcome. ${ }^{3} \mathrm{CSF}$ oligoclonal bands (OCBs) were shown to be associated with a higher risk of a second relapse and hence clinical progression from CIS to MS. ${ }^{1,4,5}$ Other CSF parameters such as intrathecal IgM synthesis, albumin ratio between CSF and blood, IgM, sCD27, chitinase like protein 3, micro RNA, IgG subclasses, and neurofilament light chain (NFL) were shown to be associated with conversion of CIS to MS, relapses, accumulation of brain lesion, and disease progression. ${ }^{6-17}$

Based on these findings, the recently revised new diagnostic MS criteria contain OCBs as a marker to demonstrate dissemination in time besides clinical and cMRI parameters. This has reinforced CSF examination during the diagnostic workup of patients with CIS and MS providing the opportunity to use CSF parameter for predicting the course of disease.

The aim of this study was to identify and confirm candidate CSF parameters potentially associated with early inflammatory disease activity as determined by cMRI and suggest a predictive score for patients newly diagnosed with CIS and MS. We decided to focus on parameters that are used in standard diagnostic workup such as intrathecal immunoglobulins and OCBs on the one hand and $\mathrm{sCD} 27$ as a marker for inflammation and B-cell differentiation and NFL as a marker for neurodegeneration on the other hand. Because early disease-modifying therapy (DMT) treatment has a major impact on MRI parameters, we assessed the predictive value of the CSF biomarker in patients who did or did not receive treatment with DMT.

\section{Methods}

\section{Patient cohort and inclusion criteria}

A total number of 149 patients with a first manifestation of MS/CIS from the Department of Neurology of the Technical University of Munich were included in this retrospective study. Patients eligible for analysis met the following criteria: (1) first clinical event suggestive of MS within the last 12 months at time of CSF sampling, (2) no further history of neurologic symptoms suggestive of an earlier disease manifestation, (3) therapy naive regarding DMT at the time of CSF sampling and baseline cMRI, (4) baseline cMRI with standardized sequences 1-3 months after initial lumbar puncture, and (5) follow-up cMRI with standardized sequences $12 \pm 3$ months after baseline cMRI. One hundred nine of 149 patients did not receive IV or oral steroid treatment within 30 days before CSF sampling.

Treatment was recorded in all patients and used for stratification of subgroups. Fifty-two patients were not treated with DMT (DMT-), and 97 patients received DMT (DMT+) during the follow-up period. Of these patients, 63 received $\beta$-interferons, 28 glatiramer acetate, 3 natalizumab, 2 dimethyl fumarate, and 1 teriflunomide. Of the 52 patients in the DMT - group, 29 declined treatment, 11 discontinued early due to side effects, 2 received delayed treatment after 7 months, and 2 became pregnant. In 8 patients, treatment was not recommended by the treating physician.

The study was approved by the ethics committee of the Technical University of Munich. Written informed consent was obtained from every participant.

\section{CSF and serum analysis}

CSF and serum were collected during diagnostic workup between 2008 and 2014. In a subset of patients, CSF and sera were aliquoted and stored for later analyses at $-80^{\circ} \mathrm{C}$. Samples underwent routine diagnostic analysis, which included detection of OCBs through isoelectric focusing and silver staining and measuring of IgG, IgM, IgA, albumin, and protein concentrations by nephelometry. Intrathecal synthesis of immunoglobulins (IgG, IgA, and IgM) was calculated according to Reiber formula. ${ }^{18}$ Immunoglobulin indices were calculated as follows: $\operatorname{IgX}-\operatorname{Index}=[\operatorname{IgX}(\mathrm{CSF}) / \operatorname{IgX}($ serum $)] /$ [Albumin (CSF)/Albumin (serum)]. Thirteen patients underwent lumbar puncture at another hospital. In this case, externally analyzed CSF data were acquired and included in this study. As standard diagnostic CSF workup can vary from hospital to hospital, some parameters are missing: 2 patients have no information regarding $\operatorname{IgM}$ and 6 patients regarding IgA.

From 84 patients, frozen CSF samples were available for further analysis, which included testing for levels of sCD27 and NFL using commercially available ELISA kits (sCD27: Human sCD27 Instant ELISA; eBioscience, San Diego, CA; NFL: NF-light ELISA; UmanDiagnostics, Umea, Sweden) as well as determining individual IgG subclass distribution by 
measuring levels of IgG1 and IgG3 by nephelometry (Siemens BN ProSpec, Germany). As CSF has a much lower concentration of $\mathrm{sCD} 27$ than serum and the applied ELISA kit was designed for serum analysis, we did not comply to the manufacturer's instructions to dilute the samples 1:25 but used undiluted CSF.

Because of small sample volumes, experiments were performed in single wells. Of the 84 patients with frozen CSF samples, 61 also had sufficient amounts of stored serum, which was subsequently analyzed together with matched CSF samples in regard to IgG1 and IgG3 levels by nephelometry. IgG1 and IgG3 indices were then calculated as above.

\section{MRI}

The first scan (baseline cMRI) was performed 1-3 months after lumbar puncture; the second scan (follow-up cMRI) was performed $12 \pm 3$ months after baseline cMRI. Activity on cMRI was defined as the appearance of new T2 hyperintense and/or new gadolinium enhancing lesions on follow-up cMRI. Brain images were all acquired on the same $3 \mathrm{~T}$ Philips scanner.

The scanning protocol included 3D gradient echo (GRE) T1weighted $(\mathrm{w})$ sequence before and after gadolinium injection (orientation, 170 contiguous sagittal $1 \mathrm{~mm}$ slices; field of view, $240 \times 240 \mathrm{~mm}$; voxel size, $1.0 \times 1.0 \mathrm{~mm}$; repetition time [TR], $9 \mathrm{~ms}$; echo time [TE], $4 \mathrm{~ms}$ ) and 3D fluid attenuated inversion recovery (FLAIR) sequence (orientation, 144 contiguous axial $1.5 \mathrm{~mm}$ slices; field of view, $230 \times 185 \mathrm{~mm}$; voxel size, $1.0 \times 1.5 \mathrm{~mm}$; TR, 10,000 ms; TE, $140 \mathrm{~ms}$; inversion time, $2,750 \mathrm{~ms}$ ).

Baseline cMRI data were analyzed in regard to lesion count, lesion load, and existence of gadolinium enhancing lesions. T2-hyperintense lesions were segmented from FLAIR and T1-weighted images by a lesion growth algorithm ${ }^{19}$ as implemented in the lesion segmentation tool toolbox version 2.0.15 (statistical-modelling.de/lst.html) for SPM12 (fil.ion. ucl.ac.uk/spm). Seven cMRIs (4.7\%) did not follow our standardized protocol and were thus excluded.

\section{Statistical analysis}

The distribution of quantitative data is described by median and range. Qualitative data are presented by absolute and relative frequencies. Associations of potential risk factors to the binary outcome cMRI activity are analyzed by univariable and multivariable logistic regression models and quantified by respective ORs with 95\% CIs. Univariable models were fit to the whole study cohort while inclusion of an interaction term between the respective risk factor and a dummy variable coding DMT+ and DMT- patients allowed to estimate effect sizes within and to test the difference between these subgroups. The multivariable model made use of gender, DMT, OCBs, IgG, IgM, IgA (indices and synthesis), lesion volume, and lesion count in a stepwise forward variable selection that was based on Akaike's information criterion. The prognostic strength of the resulting model was assessed by the area under the curve (AUC) of the receiver operating characteristic (ROC) curve. Further multivariable models were fit in a separate analysis to assess the additional prognostic value of CSF. Therefore a baseline model including gender, DMT, lesion volume, and lesion count in the baseline cMRI was compared against another model that extended this list of covariates to include further CSF parameters such as OCBs, IgG, IgM, and IgA (indices and synthesis). The diagnostic strength of the models was again quantified by the AUC. The difference was tested by a likelihood ratio test of these nested models. To depict the correlation between sCD27 and IgG index, we used Pearson correlation coefficient. All analyses were performed using R 3.5.0 (The R Foundation for Statistical Computing, Vienna, Austria). Hypothesis testing was conducted on exploratory 2 -sided $5 \%$ significance levels. As this was an exploratory study, we did not correct for multiple comparisons.

\section{Data availability statement}

The data that support the findings of this study are available from the corresponding author on reasonable request. The data are not publicly available to protect the privacy of the participating patients.

\section{Results}

\section{Study cohort}

From the 149 patients analyzed in our retrospective study, 52 patients did not start DMT within 6 months after baseline cMRI or discontinued medication again after less than 6 months. The remaining 97 patients received DMT for at least 6 months. DMT+ and DMT-patients were comparable in regard to age, sex distribution, and time between symptom onset and first MRI (table 1). In 81 patients, we observed disease activity by cMRI between the baseline and follow-up scan after 12 months.

\section{Intrathecal IgG, IgM, and IgA synthesis}

We analyzed the association between intrathecal IgG synthesis determined by the IgG index and the occurrence of new MRI lesions by logistic regression. The IgG index was associated with new cMRI lesions after 12 months (OR 3.441, CI 1.482-9.206; $p=0.008$, table 2). When we stratified the cohort according to DMT treatment, the effect was more pronounced in the DMT- patients (OR 32.021, CI $1.574-651.251 ; p=0.024$ ) than DMT+ patients (OR 2.090, CI 0.787-5.553; $p=0.139$, table 2 ). We also determined intrathecal IgG synthesis using Reiber formula. Intrathecal IgG synthesis was observed in 50\% of patients. DMTpatients with intrathecal IgG synthesis had a higher risk of cMRI activity compared to those without intrathecal synthesis (OR 11.528, CI 2.237-59.399; $p=0.003$ ) (table 3 and figure 1 ). This effect was also seen in all patients (OR 1.517, CI 0.776-2.995; $p=0.225)$. In DMT+ patients intrathecal IgG 
Table 1 Baseline characteristics of patient cohorts

\begin{tabular}{|c|c|c|c|}
\hline & MS/CIS all & MS/CIS DMT- & MS/CIS DMT+ \\
\hline \multicolumn{4}{|l|}{ Demographic data } \\
\hline No. of patients [n] & 149 & 52 & 97 \\
\hline Sex female [n (\%)] & $101(68)$ & $32(62)$ & $69(71)$ \\
\hline Age [median (range)] & $33(18-55)$ & $33.5(19-52)$ & $33(18-55)$ \\
\hline Median time symptom onset to cMRI [d (range)] & $67(1-345)$ & $64.5(1-230)$ & $67(1-345)$ \\
\hline Patients with MRI progression [n (\%)] & $81(54)$ & $37(71)$ & $44(45)$ \\
\hline \multicolumn{4}{|l|}{ cMRI data } \\
\hline Lesion volume [median (mL) (range)] & $2.106(0.093-35.872)$ & $1.489(0.093-26.762)$ & $2.383(0.140-35.872)$ \\
\hline Lesion number $>9[\mathrm{n}(\%)]$ & $93(62)$ & $26(50)$ & $67(69)$ \\
\hline Impaired blood CSF barrier [n (\%)] & $40(27)$ & $12(23)$ & $28(29)$ \\
\hline T2 lesion increment [median (range)] & $1(0-15)$ & $1(0-8)$ & $0(1-15)$ \\
\hline \multicolumn{4}{|l|}{ CSF data } \\
\hline OCB + [n (\%)] & $116(78)$ & $38(67)$ & $78(80)$ \\
\hline Intrathecal IgG [n (\%)] & $75(50)$ & $25(48)$ & $50(52)$ \\
\hline Intrathecal IgM [n (\%)] & $20(14)$ & $9(17)$ & $11(12)$ \\
\hline Intrathecal IgA [n (\%)] & $11(8)$ & $7(14)$ & $4(4)$ \\
\hline IgG index [median (range)] & $0.74(0.25-3.20)$ & $0.74(0.41-2.69)$ & $0.74(0.25-3.20)$ \\
\hline IgM index [median (range)] & $0.08(0.00-0.67)$ & $0.08(0.00-0.67)$ & $0.08(0.00-0.51)$ \\
\hline IgA index [median (range)] & $0.27(0.00-0.80)$ & $0.28(0.19-0.65)$ & $0.26(0.00-0.80)$ \\
\hline Cell count [median $(/ \mu \mathrm{l})$ (range)] & $7(0-126)$ & $10(0-126)$ & $6(0-46)$ \\
\hline
\end{tabular}

Abbreviations: $\mathrm{CIS}=$ clinically isolated syndrome; $\mathrm{CMRI}=$ cerebral MRI; DMT = disease-modifying therapy; OCB = oligoclonal band.

Patients with MS/CIS were divided into 3 groups: all patients, patients with, and patients without DMT. These were compared regarding demographic, MRI, and CSF data.

synthesis was not associated with cMRI activity (OR 0.742, CI $0.332-1.661 ; p=0.468$, table 3 ).

Analysis of the relation of intrathecal IgM synthesis on cMRI activity showed that a higher IgM index was associated with cMRI activity after 12 months (OR 43.370, CI 1.177-2,914.982; $p=0.056)$ (table 2). The effect was more pronounced in DMTpatients (OR after correction by Firth method 5,970.034, CI 0.508-70098464.401; $p=0.069)$ than DMT+ patients (OR 5.092, CI 0.065-396.140; $p=0.464$ ) (table 2). We stratified patients into those with and without intrathecal IgM synthesis according to Reiber formula. Overall $14 \%$ of patients had intrathecal IgM synthesis. Of the 20 patients with intrathecal IgM synthesis, 15 showed cMRI activity in the follow-up scan (OR 2.861, CI 0.993-9.572; $p=0.064$ ) (table 3 and figure 1). All 9 DMT- patients with intrathecal IgM showed cMRI activity during the first 12 months (OR 11.630, CI 0.544-248.843; $p=$ $0.116)$ but only 6 out of 11 in DMT+ patients (table 3 ).

We found a negative association of the IgA index with cMRI activity in DMT+ patients and only a marginal positive effect in
DMT- patients (table 2). Intrathecal IgA synthesis according to Reiber formula was detected in only $8 \%$ of all patients ( $\mathrm{n}=$ 11) and was negatively associated with a higher risk for cMRI activity regardless of treatment status (table 3 and figure 1).

In a subgroup of patients, we analyzed the IgG subclasses 1 and 3 in CSF as well as respective indices (table 2).

We found that elevated IgG1 indices were positively associated with cMRI progression (OR 1.391, CI 0.645-3.314; $p=$ $0.416)$. This effect was more pronounced in DMT- patients (OR 9.876, CI 0.503-194.019; $p=0.132$ ) but not in DMT+ patients (OR 0.780, CI 0.279-2.179; $p=0.636$ ). Elevated IgG1 levels in CSF were associated with a higher risk of cMRI activity (OR 1.023, CI 1.003-1.048; $p=0.039$ ). The effect was stronger in DMT- patients than DMT+ patients (table 2).

In all patients, IgG3 indices were not associated with cMRI progression (OR 1.001, CI 0.086-13.063; $p=0.999$ ). Independent analysis of DMT+ and DMT- patients showed a positive association in untreated patients (OR 2.558, CI 
Table 2 Comparison of CMRI progression risk in patients with MS/CIS in regard to CSF laboratory findings

\begin{tabular}{|c|c|c|c|c|}
\hline & All patients & DMT- & & DMT+ \\
\hline MS/CIS & MRI+/MRI- & MRI+/MRI- & & MRI+/MRI- \\
\hline \multicolumn{5}{|l|}{ IgG index } \\
\hline Median & $0.81 / 0.69$ & $0.81 / 0.53$ & & $0.74 / 0.73$ \\
\hline$p$ Value & 0.008 & 0.024 & & 0.139 \\
\hline OR & 3.441 & 32.021 & & 2.090 \\
\hline Cl & $1.482-9.206$ & $1.574-651.251$ & & $0.787-5.553$ \\
\hline$p$ Value of interaction & & & 0.091 & \\
\hline \multicolumn{5}{|l|}{ IgM index } \\
\hline Median & $0.09 / 0.07$ & $0.1 / 0.05$ & & $0.08 / 0.08$ \\
\hline$p$ Value & 0.056 & $0.069^{a}$ & & $0.464^{a}$ \\
\hline OR & 43.370 & $5,970.034^{a}$ & & $5.092^{a}$ \\
\hline Cl & $1.177-2,914.982$ & $0508-70098464.401^{a}$ & & $0.065-396.140^{a}$ \\
\hline$p$ Value of interaction & & & 0.145 & \\
\hline \multicolumn{5}{|l|}{ IgA index } \\
\hline Median & $0.27 / 0.26$ & $0.28 / 0.25$ & & $0.26 / 0.26$ \\
\hline$p$ Value & 0.884 & 0.990 & & 0.847 \\
\hline OR & 0.781 & 1.035 & & 0.662 \\
\hline $\mathrm{Cl}$ & $0.027-23.249$ & $0.004-254.431$ & & $0.010-44.463$ \\
\hline$p$ Value of interaction & & & 0.899 & \\
\hline \multicolumn{5}{|l|}{ IgG1 index } \\
\hline Median & $0.63 / 0.62$ & $0.72 / 0.58$ & & $0.6 / 0.66$ \\
\hline$p$ Value & 0.416 & 0.132 & & 0.636 \\
\hline OR & 1.391 & 9.876 & & 0.780 \\
\hline Cl & $0.645-3.314$ & 0.503-194.019 & & $0.279-2.179$ \\
\hline$p$ Value of interaction & & & 0.115 & \\
\hline \multicolumn{5}{|l|}{ IgG1 (mg/L) } \\
\hline Median & $27.85 / 23.2$ & $35 / 19.55$ & & $25.3 / 24.4$ \\
\hline$p$ Value & 0.039 & 0.052 & & 0.338 \\
\hline OR & 1.023 & 1.059 & & 1.012 \\
\hline Cl & $1.003-1.048$ & $1.000-1.122$ & & $0.988-1.036$ \\
\hline$p$ Value of interaction & & & 0.149 & \\
\hline \multicolumn{5}{|l|}{ IgG3 index } \\
\hline Median & $0.34 / 0.34$ & $0.39 / 0.33$ & & $0.34 / 0.39$ \\
\hline$p$ value & 0.999 & 0.581 & & 0.385 \\
\hline OR & 1.001 & 2.558 & & 0.141 \\
\hline Cl & $0.086-13.063$ & $0.091-71.672$ & & $0.002-11.719$ \\
\hline$p$ Value of interaction & & & 0.305 & \\
\hline
\end{tabular}


Table 2 Comparison of CMRI progression risk in patients with MS/CIS in regard to CSF laboratory findings (continued)

\begin{tabular}{|c|c|c|c|}
\hline & All patients & DMT- & DMT+ \\
\hline $\mathrm{MS} / \mathrm{CIS}$ & MRI+/MRI- & MRI+/MRI- & MRI+/MRI- \\
\hline Median & $0.77 / 0.68$ & $0.68 / 0.65$ & $0.8 / 0.7$ \\
\hline$p$ Value & 0.683 & 0.397 & 0.673 \\
\hline OR & 1.130 & 1.601 & 0.826 \\
\hline $\mathrm{Cl}$ & $0.643-2.193$ & $0.539-4.758$ & $0.339-2.012$ \\
\hline$p$ Value of interaction & & & \\
\hline \multicolumn{4}{|l|}{ sCD27 (U/mL) ${ }^{b}$} \\
\hline Median & $11.72 / 9.26$ & $14.55 / 5.36$ & $11.5 / 10.12$ \\
\hline$p$ Value & 0.030 & 0.085 & 0.200 \\
\hline OR & 1.552 & 2.619 & 1.335 \\
\hline $\mathrm{Cl}$ & $1.087-2.430$ & $0.875-7.842$ & $0.858-2.075$ \\
\hline$p$ Value of interaction & & & \\
\hline \multicolumn{4}{|l|}{$\mathrm{NFL}(\mathrm{pg} / \mathrm{mL})^{\mathrm{c}}$} \\
\hline Median & $1620.84 / 644.12$ & $1959.55 / 676.52$ & $1524.98 / 634.4$ \\
\hline$p$ Value & 0.324 & 0.425 & 0.541 \\
\hline OR & 1.033 & 1.047 & 1.025 \\
\hline $\mathrm{Cl}$ & $0.971-1.107$ & $0.936-1.170$ & $0.947-1.109$ \\
\hline$p$ Value of interaction & & & \\
\hline
\end{tabular}

Abbreviations: CIS = clinically isolated syndrome; CMRI = cerebral MRI; DMT = disease-modifying therapy; NFL = neurofilament.

Patients with MS/CIS were divided into 3 groups: all patients, patients with DMT (DMT+) and patients without DMT (DMT-). Patients were compared in their risk for cMRI progression when regarding levels of immunoglobulin indices and concentrations of IgG subclasses 1 and 3, sCD27, and NFL by logistic regression.

a Corrected by Firth method.

${ }^{\mathrm{b}}$ For a 10 unit change.

${ }^{\mathrm{c}}$ For a 500 unit change.

$0.091-71.672 ; p=0.581)$ but not DMT+ patients (OR 0.141, CI $0.002-11.719 ; p=0.385)$.

\section{OCBs}

OCBs were positively associated with the occurrence of cMRI activity after 12 months in the entire cohort (OR 1.855, CI 0.824-4.279; $p=0.139)$ and in particular in DMT- patients (9.327, CI 2.296-37.890; $p=0.002$ ) but not DMT+ patients (OR 0.714, CI 0.260-1.960; $p=0.513$ ) (table 3). Of 38 DMT- patients with OCBs, 32 patients (84\%) showed new lesions in the follow-up cMRIs, whereas only 5 out of 14 patients without OCBs (36\%) (figure 1).

\section{CSF, NFL, and SCD27 levels}

We compared patients with and without cMRI activity during the first 12 months after diagnosis in regard to their levels of sCD27 in CSF and found that elevated sCD27 levels were associated with a higher risk of developing new lesions in cMRI (table 2). Patients with higher levels of sCD27 in CSF had a higher risk of new cMRI lesions during the follow-up period (OR 1.552, CI 1.087-2.430; $p=0.030$ ). The same trend was seen in DMT- patients (OR 2.619, CI $0.875-7.842 ; p=0.085)$ and to a lower extent in DMT+ patients (table 2). Interestingly, sCD27 levels were highly correlated with IgG index $\left(r=0.884, p=1.916 \times 10^{-20}\right)$. CSF NFL levels showed a marginal positive association in our cohort with new cMRI activity after 12 months regardless of treatment status (table 2).

\section{Multivariable analysis of CSF laboratory in all patients}

We performed a multivariable logistic regression analysis to identify parameters that were mutually associated with MRI progression. Because of sample size, we decided to focus on the entire cohort and did not analyze DMT+ and DMT-patients independently. We also did not include sCD27 because data were only available on a subgroup of patients and sCD27 strongly correlated with the IgG index. IgG index, DMT, gender distribution, IgM index, and intrathecal IgA synthesis were selected into the model as the most important variables (table 4). Higher IgG indices were found to be associated with a higher risk of cMRI progression 
Table 3 Risk of CMRI progression in patients with and without intrathecal immunoglobulin synthesis and OCBs

\begin{tabular}{|c|c|c|c|}
\hline & All patients & DMT-patients & DMT+ patients \\
\hline MS/CIS & MRI+/- & MRI+/- & MRI+/- \\
\hline Patients with IgG synthesis [n (\%)] & $44(54 \%) / 31(46 \%)$ & $23(62 \%) / 2(13 \%)$ & $21(48 \%) / 29(55 \%$ \\
\hline$p$ Value & 0.225 & 0.003 & 0.468 \\
\hline OR & 1.517 & 11.528 & 0.742 \\
\hline $\mathrm{Cl}$ & $0.776-2.995$ & $2.237-59.399$ & $0.332-1.661$ \\
\hline$p$ Value of interaction & & & \\
\hline Patients with IgM synthesis [n (\%)] & $15(19 \%) / 5(8 \%)$ & $9(24 \%) / 0(0 \%)$ & $6(14 \%) / 5(10 \%)$ \\
\hline$p$ Value & 0.064 & $0.116^{a}$ & $0.511^{a}$ \\
\hline OR & 2.861 & $11.630^{\mathrm{a}}$ & $1.533^{a}$ \\
\hline $\mathbf{C l}$ & $0.993-9.572$ & $0.544-248.843^{a}$ & $0.428-5.489^{a}$ \\
\hline$p$ Value of interaction & & & \\
\hline Patients with IgA synthesis [n (\%)] & $6(7 \%) / 5(8 \%)$ & $5(14 \%) / 2(14 \%)$ & $1(2 \%) / 3(6 \%)$ \\
\hline$p$ Value & 0.516 & 0.937 & 0.390 \\
\hline OR & 0.648 & 0.931 & 0.364 \\
\hline $\mathrm{Cl}$ & $0.171-2.496$ & $0.159-5.471$ & $0.036-3.649$ \\
\hline$p$ Value of interaction & & & \\
\hline Patients with CSF OCBs [n (\%)] & $66(82 \%) / 50(74 \%)$ & $32(86 \%) / 6(40 \%)$ & $34(77 \%) / 44(83 \%)$ \\
\hline$p$ Value & 0.139 & 0.002 & 0.513 \\
\hline OR & 1.855 & 9.327 & 0.714 \\
\hline $\mathrm{Cl}$ & $0.824-4.279$ & $2.296-37.890$ & $0.260-1.960$ \\
\hline$p$ Value of interaction & & & \\
\hline
\end{tabular}

Abbreviations: $\mathrm{CIS}=$ clinically isolated syndrome; $\mathrm{CMRI}=$ cerebral MRI; DMT = disease-modifying therapy; OCB = oligoclonal band.

Patients with MS/CIS were divided into 3 groups: all patients, patients with DMT (DMT+), and patients without DMT (DMT-). Patients were compared in their risk for CMRI progression when regarding intrathecal immunoglobulin G, M, and A synthesis and presence of OCBs by logistic regression.

a Corrected by Firth method.

(OR 3.144, CI 1.156-8.554; $p=0.025$ ). As expected, DMT was also associated with an decreased risk of cMRI activity. Surprisingly in our cohort, female gender was associated with a higher risk of cMRI activity. Mean IgM indices were higher in patients with cMRI progression than in patients without (OR 115.834, CI 0.923-14,531.160; $p=0.054$ ). Intrathecal IgA synthesis was associated with less cMRI activity when using a multivariable analysis (OR 0.274, CI 0.058-1.292; $p=$ $0.10172)$. The ROC analysis resulted in an AUC of $0.734(p<$ 0.001 ), which underlines the prognostic benefit of these variables (figure $2 \mathrm{~A}$ ).

\section{Prognostic value of cMRI vs CSF findings}

To emphasize the additional prognostic value of CSF parameters in comparison to cMRI data, we computed 2 additional multivariable models. Gender, DMT, lesion volume, and lesion count in the baseline cMRI resulted in a model with an AUC of 0.679. Combined analysis with CSF parameters such as OCBs, intrathecal IgG, IgM, IgA synthesis, and their respective indices increased the prognostic strength of the model to an AUC of $0.751(p=0.025)$ (figure 2B).

\section{Quantitative prediction of cMRI activity}

To estimate a patient's individual risk for future cMRI activity, we computed a numeric risk scale using the regression parameters of our multivariable model (figure 3). Values of each factor are assigned to a specific number of points and addition of these leads to a cumulative score. This score then can be converted to predict the patient's probability of future cMRI activity.

\section{Discussion}

In the present study, we investigated the predictive value of CSF parameters at the time of diagnosis of CIS and MS for the development of new lesions on a follow-up cMRI after 12 months. 

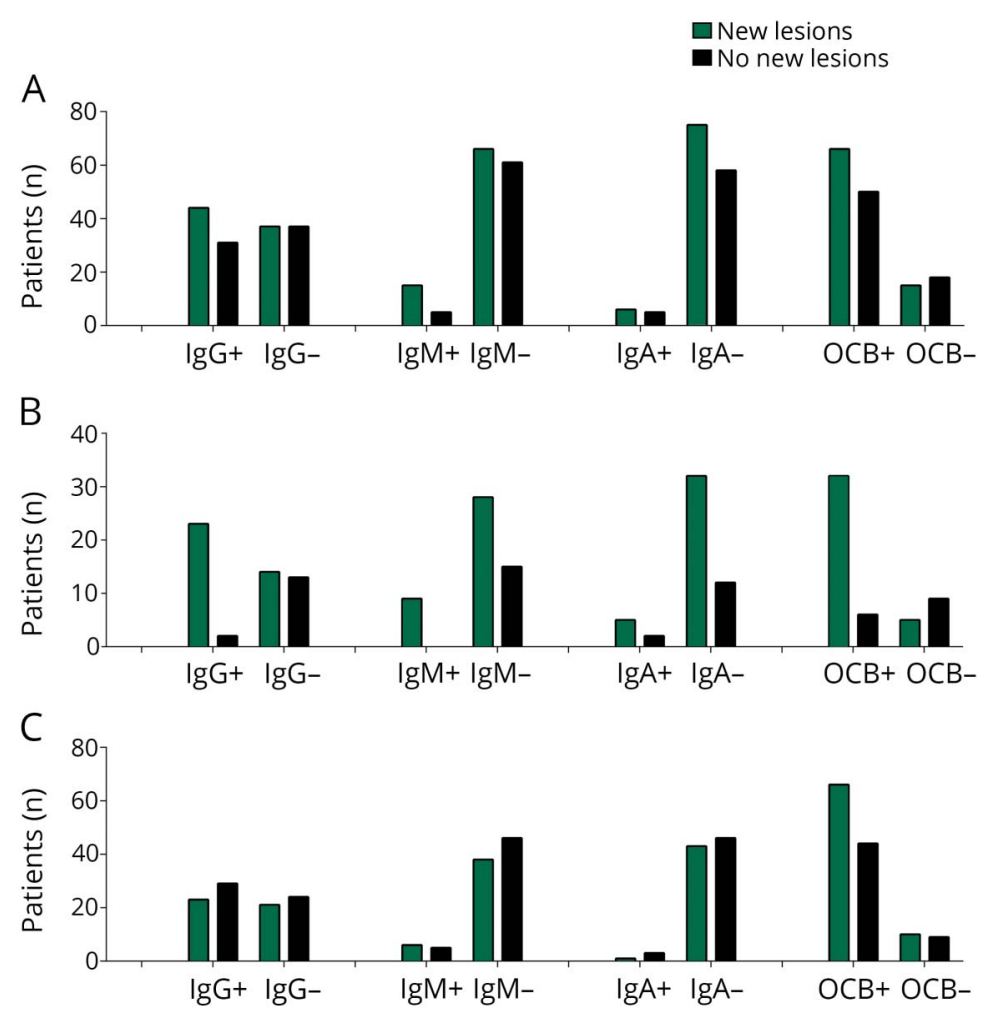

The number of patients with and without intrathecal IgG, IgM, and IgA synthesis and oligoclonal bands are shown and compared regarding CMRI progression during the first 12 months. White columns $=$ patients with new lesions. Black columns = patients without new lesions. (A) All patients, (B) only patients without DMT, and $(C)$ only patients receiving DMT. DMT = disease-modifying therapy; OCB = oligoclonal band.

Routine diagnostic workup of patients with CIS/MS usually entails the detection of IgG either in form of OCBs or quantitative intrathecal synthesis as shown by IgG index (usually $>0.7$ ) or Reiber formula. Many labs also measure IgM and IgA levels in CSF. As mentioned above in particular intrathecal IgG synthesis seems to be associated with earlier inflammatory disease activity leading to our inclusion of these parameters in this study. sCD27 is the soluble version of the surface molecule CD27 that belongs to the TNFreceptor family and can be found on $\mathrm{B}$ - and T-cells. It plays an important role in B-cell differentiation and immunoglobulin synthesis. Because patients with MS were found to have higher levels of the soluble version of this molecule, ${ }^{20}$ we also included this parameter in our analysis. The same applies to NFL, which has been shown to be associated with neuronal damage and brain atrophy in patients with relapsing-remitting $\mathrm{MS}^{12,13,21-23}$

We demonstrate that soluble CD27 levels in CSF, IgG1 levels, IgG index, and possibly IgM index at the time of diagnosis are associated with cMRI activity during the next 12 months in our retrospective study. In the subgroup of patients who had not been treated with DMT, sCD27, IgG1 levels, OCBs in $\mathrm{CSF}, \mathrm{IgG}$ and possible IgM indices are associated with future cMRI activity. In the multivariable analysis, IgG index, IgM index, and intrathecal IgA synthesis, besides DMT treatment status and gender, are the main variables predicting future cMRI activity in our cohort.
Until now, CSF examination in patients presenting with suspected CIS or MS mainly serves diagnostic purposes, which might be at least partially due to the lack of studies systematically analyzing CSF parameters in patients presenting with a first clinical event suggestive of MS. Most studies conducted in the past dealing with a potentially prognostic value of CSF parameters did not discriminate between patients who started DMT during follow-up and those who did not. In our cohort, DMT has an influence on cMRI activity even within a short follow-up period of 12 months, which is in line with many previous studies. ${ }^{1,24-28}$ For this

Table 4 Multivariable analysis of CSF laboratory findings in all patients

\begin{tabular}{llll}
\hline & $\boldsymbol{p}$ Value & OR & Cl \\
\hline IgG index & 0.025 & 3.144 & $1.156-8.554$ \\
\hline DMT & 0.002 & 0.249 & $0.105-0.594$ \\
\hline Gender & 0.028 & 2.506 & $1.107-5.672$ \\
\hline IgM index & 0.054 & 115.834 & $0.923-14,531.16$ \\
\hline Intrathecal IgA synthesis & 0.102 & 0.274 & $0.058-1.292$ \\
\hline
\end{tabular}

Abbreviations: CIS = clinically isolated syndrome; DMT = disease-modifying therapy.

Potentially prognostic biomarkers in patients with MS/CIS were analyzed by multivariable logistic regression to obtain $p$-values, $\mathrm{OR}$, and $\mathrm{Cl}$. 

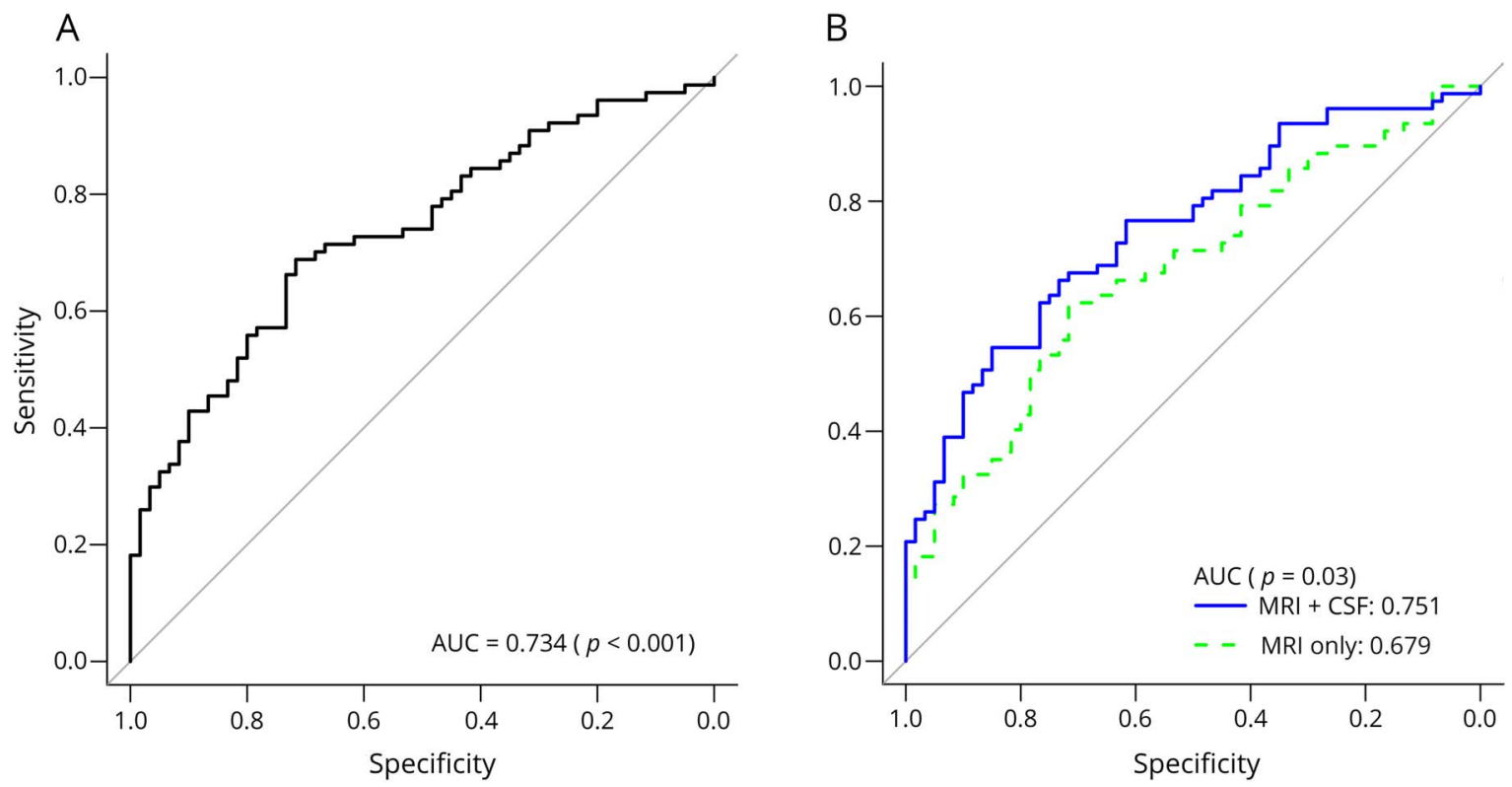

(A) Analysis of potentially prognostic biomarkers inpatients with MS/CIS through multivariable logistic regression lead to selection of IgG index, DMT, gender distribution, IgM index, and intrathecal IgA synthesis. A ROC analysis resulted in an AUC of $0.734(p<0.001)$. (B) The prognostic value of cMRI parameters including cMRI lesion load and lesion volume and baseline information such as gender distribution and DMT were compared to the additional prognostic value when including CSF parameters and shown in an ROC curve. AUC of MRI parameters alone was 0.679, AUC of MRI and CSF parameters combined was $0.751(p=0.03)$. AUC = area under the curve; $\mathrm{CIS}=$ clinically isolated syndrome; $\mathrm{CMRI}=$ cerebral MRI; DMT = disease-modifying therapy; $\mathrm{ROC}=$ receiver operating characteristic.

reason, we decided to discriminate between patients with and without DMT to exclude the effect of this confounding factor.

Moreover, in the studies conducted so far, progression has been mainly defined by clinical outcome parameters, and follow-up time periods varied largely even within patient cohorts. As clinical relapses are sometimes challenging to discern precisely from anamnestic information in clinical routine and calculation of Expanded Disability Status Scale (EDSS) scores (especially of lower values) varies from day to day depending on a patient's physical state as well as the individual examiner, we concluded that MRI offers a more sensitive and objective parameter to detect disease activity, especially when MRI scanning is performed in a highly standardized fashion.

Overall our findings are in line with previous studies suggesting a predictive role of intrathecal IgG synthesis, IgM synthesis, and the presence of OCBs for predicting future clinical disease activity. The presence of OCBs in the CSF is a known risk factor for conversion to MS in patients with CIS. ${ }^{1,2,5}$ The same applies to quantitative measures of IgG and IgM synthesis in the CSF compartment. ${ }^{29}$ Little is known about how $\operatorname{IgG} 1$ and IgG3 levels in serum and CSF relate to future disease activity. Increased IgG1 levels in CSF are found in patients with CIS and MS. ${ }^{30,31}$ We observed an association of IgG1 levels in CSF and future MRI activity. However, this analysis was based on only a smaller subset of our cohort and the IgG1 index itself may have shown a positive association with cMRI activity but failed to reach the level of significance. A recent study reported an association of higher serum IgG3 levels with faster conversion to MS in patients with CIS. ${ }^{32}$ However, this study was based on a small cohort of patients. We did observe a slight positive association of IgG3 levels in CSF with MRI activity; however, once again this trend failed to reach significance. Also sCD27 levels in CSF seem to be associated with conversion to MS and future relapse activity in adults and children with CIS. ${ }^{9,33}$ Our findings of an association between $\mathrm{SCD}^{27}$ in CSF with MRI activity are in line with these studies. However, IgG index and sCD27 levels in CSF are highly correlated suggesting that they are not independent biomarkers and rather depict markers of humoral inflammation in the CNS compartment. Most studies reported NFL in CSF or serum as a predictive marker for future disease activity. ${ }^{16,34}$ Although we observed a trend in the same direction, the effect was small in our study and did not reach the level of significance, which might be due to the low number of patients in the NFL analysis.

In summary, we provide evidence that IgG index and to a lesser extent IgM and IgA index are helpful markers to predict future MRI activity in particular if they are combined with other variables such as DMT status and gender distribution. Establishing reliable risk scores for patients with newly diagnosed CIS or MS might be very helpful to guide early treatment decisions. Such a risk score might include other biomarkers (e.g., microRNA and chitinase-like protein ${ }^{14,16,17}$ ) or imaging parameters (e.g., spinal $\mathrm{MRI}^{35}$ ). As our cohort only entails a small number of patients, further studies with larger cohorts are warranted to validate these findings. 
Figure 3 Risk calculator (nomogram) for future cMRI activity in patients with MS/CIS

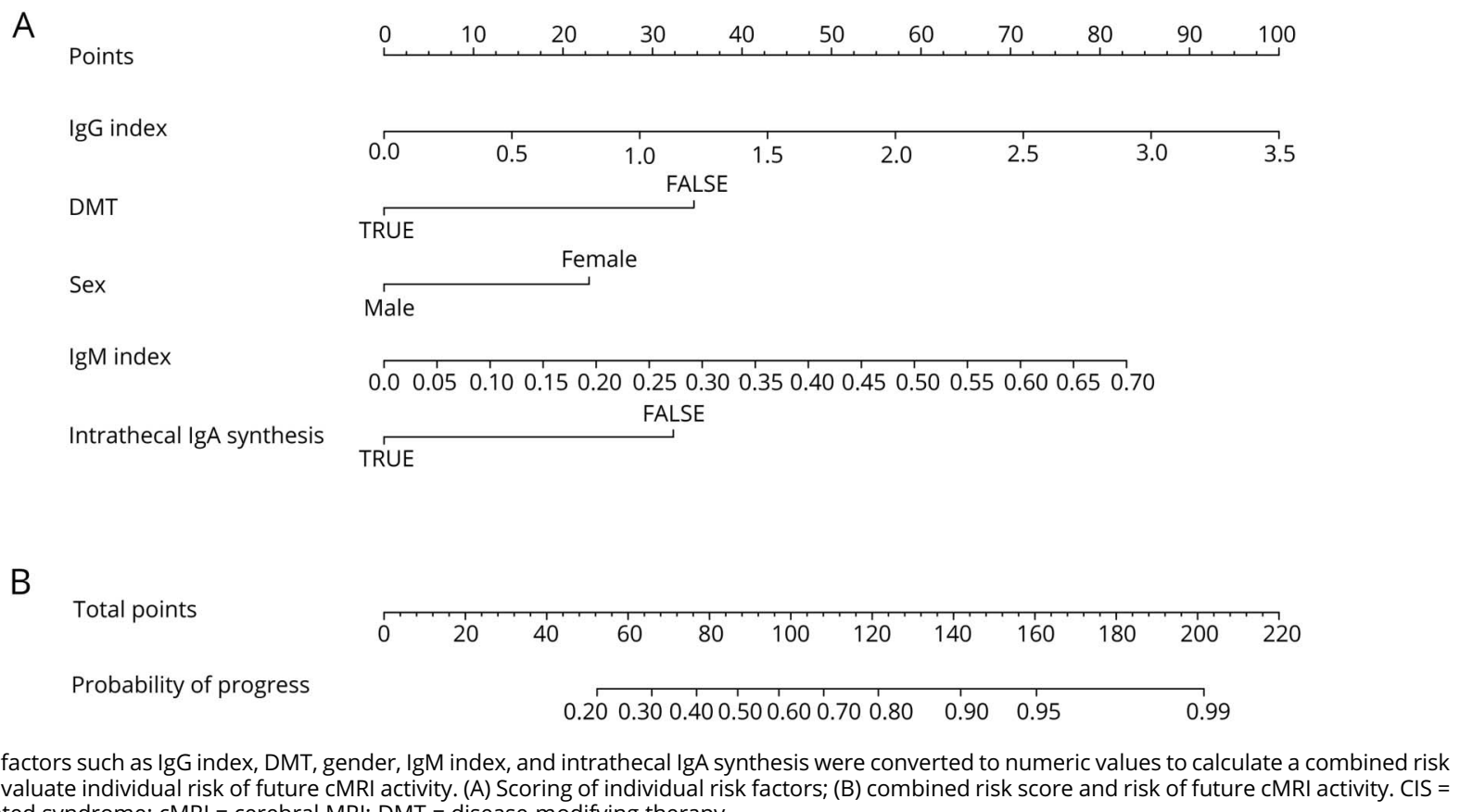

Potential risk factors such as IgG index, DMT, gender, IgM index, and intrathecal IgA synthesis were converted to numeric values to calculate a combined risk
score to the evaluate individual risk of future cMRI activity. (A) Scoring of individual risk factors; (B) combined risk score and risk of future cMRI activity. CIS = clinically isolated syndrome; cMRI = cerebral MRI; DMT = disease-modifying therapy.

\section{Acknowledgment}

The authors express their deep thankfulness to all contributors of the study, especially the study nurses, for their motivated collaboration and recruitment efforts, all patients for their participation.

\section{Study funding}

The study was supported by grants from the German Federal Ministry for Education and Research Competence network Multiple Sclerosis (BMBF, 01GI1601D) and DiFuture (Data Integration for Future Medicine, BMBF 01ZZ1804[A-F]). Biosamples were provided by the biobank of the Department of Neurology as part of the Joined Biobank Munich in the framework of the German Biobank node. Bernhard Hemmer received funding for the study from the Multiple MS EU Consortium and the SFB CRC 128.

\section{Disclosure}

A. Klein and R. Selter reports no disclosures. A. Hapfelmeier received a honorarium from Biogen for consulting services for the Biogen Symposium on Statistical Methods in Real World Evidence 2017. A. Berthele reports grants from Bayer HealthCare, personal fees from Biogen, Merck Serono, Teva, Novartis, and Genzyme, and compensations for clinical trials from Biogen, Novartis, Genzyme, Roche, Teva, and Alexion Pharmaceuticals. B. Müller-Myhsok reports no disclosures. V. Pongratz received research funding from Novartis (Oppenheim Förderpreis 2017). C. Gasperi reports no disclosures. C. Zimmer served on the scientific advisory board for Philips, received speaker honoraria from Bayer Schering, Philips, serves as co-editor on the advisory board of Clinical Neuroradiology. M. Mühlau received research support from Merck Serono and Novartis as well as travel expenses for attending meetings from Merck Serono. B. Hemmer has served on scientific advisory board for Novartis; he has served as DMSC member for AllergyCare and TG Therapeutics; he or his institution have received speaker honoraria from Desitin; holds part of 2 patents, one for the detection of antibodies against KIR4.1 in a subpopulation of patients with MS and one for genetic determinants of neutralizing antibodies to interferon $\beta$. All disclosures were outside the submitted work. Go to Neurology.org/NN for full disclosures.

\section{Publication history}

Received by Neurology: Neuroimmunology \& Neuroinflammation June 28, 2018. Accepted in final form March 21, 2019.

\begin{tabular}{llll}
\multicolumn{2}{l}{ Appendix } & Authors & \\
\hline Authors & Location & Role & Contribution \\
\hline $\begin{array}{lll}\text { Ana Klein, } \\
\text { MD }\end{array}$ & $\begin{array}{l}\text { Technische } \\
\text { Universität } \\
\text { München, } \\
\text { Germany }\end{array}$ & Author & $\begin{array}{l}\text { Designed and } \\
\text { conceptualized the } \\
\text { study; performed data } \\
\text { acquisition, analysis, } \\
\text { and interpretation; } \\
\text { drafted the manuscript } \\
\text { for intellectual content }\end{array}$ \\
& & Author & $\begin{array}{l}\text { Performed data } \\
\text { acquisition, analysis, } \\
\text { and interpretation; } \\
\text { revised the manuscript } \\
\text { for intellectual content }\end{array}$ \\
\hline Rebecca C. & Technische & &
\end{tabular}


Appendix (continued)

\begin{tabular}{|c|c|c|c|}
\hline Authors & Location & Role & Contribution \\
\hline $\begin{array}{l}\text { Alexander } \\
\text { Hapfelmeier, } \\
\text { PhD }\end{array}$ & $\begin{array}{l}\text { Technische } \\
\text { Universität } \\
\text { München, } \\
\text { Germany }\end{array}$ & Author & $\begin{array}{l}\text { Performed data analysis } \\
\text { and interpretation; } \\
\text { revised the manuscript } \\
\text { for intellectual content }\end{array}$ \\
\hline $\begin{array}{l}\text { Achim } \\
\text { Berthele, MD }\end{array}$ & $\begin{array}{l}\text { Technische } \\
\text { Universität } \\
\text { München, } \\
\text { Germany }\end{array}$ & Author & $\begin{array}{l}\text { Revised the manuscript } \\
\text { for intellectual content }\end{array}$ \\
\hline $\begin{array}{l}\text { Bertram } \\
\text { Müller- } \\
\text { Myhsok, PhD }\end{array}$ & $\begin{array}{l}\text { Max-Planck- } \\
\text { Institute of } \\
\text { Psychiatry, } \\
\text { München, } \\
\text { Germany }\end{array}$ & Author & $\begin{array}{l}\text { Aided in data analysis; } \\
\text { revised the manuscript } \\
\text { for intellectual content }\end{array}$ \\
\hline $\begin{array}{l}\text { Viola } \\
\text { Pongratz, MD }\end{array}$ & $\begin{array}{l}\text { Technische } \\
\text { Universität } \\
\text { München, } \\
\text { Germany }\end{array}$ & Author & $\begin{array}{l}\text { Revised the manuscript } \\
\text { for intellectual content; } \\
\text { aided in data acquisition }\end{array}$ \\
\hline $\begin{array}{l}\text { Christiane } \\
\text { Gasperi, MD }\end{array}$ & $\begin{array}{l}\text { Technische } \\
\text { Universität } \\
\text { München, } \\
\text { Germany }\end{array}$ & Author & $\begin{array}{l}\text { Revised the manuscript } \\
\text { for intellectual content }\end{array}$ \\
\hline $\begin{array}{l}\text { Claus } \\
\text { Zimmer, MD }\end{array}$ & $\begin{array}{l}\text { Technische } \\
\text { Universität } \\
\text { München, } \\
\text { Germany }\end{array}$ & Author & $\begin{array}{l}\text { Revised the manuscript } \\
\text { for intellectual content }\end{array}$ \\
\hline $\begin{array}{l}\text { Mark } \\
\text { Mühlau, MD }\end{array}$ & $\begin{array}{l}\text { Technische } \\
\text { Universität } \\
\text { München, } \\
\text { Germany }\end{array}$ & Author & $\begin{array}{l}\text { Revised the manuscript } \\
\text { for intellectual content; } \\
\text { aided in data acquisition }\end{array}$ \\
\hline $\begin{array}{l}\text { Bernhard } \\
\text { Hemmer, MD }\end{array}$ & $\begin{array}{l}\text { Technische } \\
\text { Universität } \\
\text { München, } \\
\text { Germany }\end{array}$ & Author & $\begin{array}{l}\text { Designed and } \\
\text { conceptualized the } \\
\text { study; performed data } \\
\text { analysis and } \\
\text { interpretation; drafted } \\
\text { the manuscript for } \\
\text { intellectual content }\end{array}$ \\
\hline
\end{tabular}

\section{References}

1. Tintore M, Rovira A, Rio J, et al. Defining high, medium and low impact prognostic factors for developing multiple sclerosis. Brain 2015;138:1863-1874.

2. Kuhle J, Disanto G, Dobson R, et al. Conversion from clinically isolated syndrome to multiple sclerosis: a large multicentre study. Mult Scler 2015;21:1013-1024.

3. Fisniku LK, Brex PA, Altmann DR, et al. Disability and T2 MRI lesions: a 20-year followup of patients with relapse onset of multiple sclerosis. Brain 2008;131:808-817.

4. Tintore M, Rovira A, Rio J, et al. Do oligoclonal bands add information to MRI in first attacks of multiple sclerosis? Neurology 2008;70:1079-1083

5. Dobson R, Ramagopalan S, Davis A, Giovannoni G. Cerebrospinal fluid oligoclona bands in multiple sclerosis and clinically isolated syndromes: a meta-analysis of prevalence, prognosis and effect of latitude. J Neurol Neurosurg Psychiatry 2013;84:909-914.

6. Uher T, Horakova D, Tyblova M, et al. Increased albumin quotient (QAlb) in patients after first clinical event suggestive of multiple sclerosis is associated with development of brain atrophy and greater disability 48 months later. Mult Scler 2016;22:770-781.

7. Ferraro D, Simone AM, Bedin R, et al. Cerebrospinal fluid oligoclonal IgM bands predict early conversion to clinically definite multiple sclerosis in patients with clinically isolated syndrome. J Neuroimmunol 2013;257:76-81.

8. Durante L, Zaaraoui W, Rico A, et al. Intrathecal synthesis of IgM measured after a first demyelinating event suggestive of multiple sclerosis is associated with subsequent MRI brain lesion accrual. Mult Scler 2012;18:587-591.
9. van der Vuurst de Vries RM, Mescheriakova JY, Runia TF, Jafari N, Siepman TA, Hintzen RQ. Soluble CD27 levels in cerebrospinal fluid as a prognostic biomarker in clinically isolated syndrome. JAMA Neurol 2017;74:286-292.

10. Norgren N, Sundstrom P, Svenningsson A, Rosengren L, Stigbrand T, Gunnarsson M. Neurofilament and glial fibrillary acidic protein in multiple sclerosis. Neurology 2004; 63:1586-1590.

11. Disanto G, Adiutori R, Dobson R, et al. Serum neurofilament light chain levels are increased in patients with a clinically isolated syndrome. J Neurol Neurosurg Psychiatry 2016;87:126-129.

12. Kuhle J, Barro C, Disanto G, et al. Serum neurofilament light chain in early relapsing remitting MS is increased and correlates with CSF levels and with MRI measures of disease severity. Mult Scler 2016;22:1550-1559.

13. Hakansson I, Tisell A, Cassel P, et al. Neurofilament light chain in cerebrospinal fluid and prediction of disease activity in clinically isolated syndrome and relapsingremitting multiple sclerosis. Eur J Neurol 2017;24:703-712.

14. Bergman P, Piket E, Khademi M, et al. Circulating miR-150 in CSF is a novel candidate biomarker for multiple sclerosis. Neurol Neuroimmunol Neuroinflamm 2016; 3:e219. doi: 10.1212/NXI.0000000000000573.

15. Villar L, Garcia-Barragan N, Espino M, et al. Influence of oligoclonal IgM specificity in multiple sclerosis disease course. Mult Scler 2008;14:183-187.

16. Sellebjerg F, Royen L, Soelberg Sorensen P, Oturai AB, Jensen PEH. Prognostic value of cerebrospinal fluid neurofilament light chain and chitinase-3-like-1 in newly diagnosed patients with multiple sclerosis. Mult Scler 2018:1352458518794308.

17. Mollgaard M, Degn M, Sellebjerg F, Frederiksen JL, Modvig S. Cerebrospinal fluid chitinase-3-like 2 and chitotriosidase are potential prognostic biomarkers in early multiple sclerosis. Eur J Neurol 2016;23:898-905.

18. Reiber H, Felgenhauer K. Protein transfer at the blood cerebrospinal fluid barrier and the quantitation of the humoral immune response within the central nervous system. Clinica Chim Acta Int J Clin Chem 1987;163:319-328.

19. Schmidt P, Gaser C, Arsic M, et al. An automated tool for detection of FLAIR hyperintense white-matter lesions in Multiple Sclerosis. Neuroimage 2012;59: 3774-3783.

20. Hintzen RQ, van Lier RA, Kuijpers KC, et al. Elevated levels of a soluble form of the $\mathrm{T}$ cell activation antigen CD27 in cerebrospinal fluid of multiple sclerosis patients. J Neuroimmunol 1991;35:211-217.

21. Varhaug KN, Barro C, Bjornevik K, et al. Neurofilament light chain predicts disease activity in relapsing-remitting MS. Neurol Neuroimmunol Neuroinflamm 2018;5: e422. doi: 10.1212/NXI.0000000000000422.

22. Siller N, Kuhle J, Muthuraman M, et al. Serum neurofilament light chain is a biomarker of acute and chronic neuronal damage in early multiple sclerosis. Mult Scler 2018:1352458518765666.

23. Kuhle J, Nourbakhsh B, Grant D, et al. Serum neurofilament is associated with progression of brain atrophy and disability in early MS. Neurology 2017;88:826-831.

24. Comi G, Filippi M, Barkhof F, et al. Effect of early interferon treatment on conversion to definite multiple sclerosis: a randomised study. Lancet 2001;357: 1576-1582.

25. Comi G, Martinelli V, Rodegher M, et al. Effects of early treatment with glatiramer acetate in patients with clinically isolated syndrome. Mult Scler 2013;19:1074-1083.

26. Radue EW, O'Connor P, Polman CH, et al. Impact of fingolimod therapy on magnetic resonance imaging outcomes in patients with multiple sclerosis. Arch Neurol 2012;69: 1259-1269.

27. Miller DH, Soon D, Fernando KT, et al. MRI outcomes in a placebo-controlled trial of natalizumab in relapsing MS. Neurology 2007;68:1390-1401.

28. Wolinsky JS, Narayana PA, Nelson F, et al. Magnetic resonance imaging outcomes from a phase III trial of teriflunomide. Mult Scler 2013;19:1310-1319.

29. Huss A, Abdelhak A, Halbgebauer S, et al. Intrathecal immunoglobulin M production: a promising high-risk marker in clinically isolated syndrome patients. Ann Neurol 2018;83:1032-1036.

30. Greve B, Magnusson CG, Melms A, Weissert R. Immunoglobulin isotypes reveal a predominant role of type 1 immunity in multiple sclerosis. J Neuroimmunol 2001; 121:120-125

31. Di Pauli F, Gredler V, Kuenz B, et al. Features of intrathecal immunoglobulins in patients with multiple sclerosis. J Neurol Sci 2010;288:147-150.

32. Trend S, Jones AP, Cha L, et al. Higher serum immunoglobulin G3 levels may predict the development of multiple sclerosis in individuals with clinically isolated syndrome. Front Immunol 2018;9:1590.

33. Wong YYM, van der Vuurst de Vries RM, van Pelt ED, et al. T-cell activation marker SCD27 is associated with clinically definite multiple sclerosis in childhood-acquired demyelinating syndromes. Mult Scler 2018;24:1715-1724.

34. Arrambide G, Espejo C, Eixarch H, et al. Neurofilament light chain level is a weak risk factor for the development of MS. Neurology 2016;87:1076-1084.

35. Zeydan B, Gu X, Atkinson EJ, et al. Cervical spinal cord atrophy: an early marker of progressive MS onset. Neurol Neuroimmunol Neuroinflamm 2018;5:e435. doi: 10. 1212/NXI.0000000000000435. 


\section{Neurology \\ Neuroimmunology \& Neuroinflammation}

CSF parameters associated with early MRI activity in patients with MS

Ana Klein, Rebecca C. Selter, Alexander Hapfelmeier, et al.

Neurol Neuroimmunol Neuroinflamm 2019;6;

DOI 10.1212/NXI.0000000000000573

This information is current as of May 30, 2019

\section{Updated Information \& Services}

References

Subspecialty Collections

Permissions \& Licensing

Reprints including high resolution figures, can be found at:

http://nn.neurology.org/content/6/4/e573.full.html

This article cites 33 articles, 2 of which you can access for free at: http://nn.neurology.org/content/6/4/e573.full.html\#\#ref-list-1

This article, along with others on similar topics, appears in the following collection(s):

Cerebrospinal Fluid

http://nn.neurology.org//cgi/collection/cerebrospinal_fluid

MRI

http://nn.neurology.org//cgi/collection/mri

Multiple sclerosis

http://nn.neurology.org//cgi/collection/multiple_sclerosis

Information about reproducing this article in parts (figures,tables) or in its entirety can be found online at:

http://nn.neurology.org/misc/about.xhtml\#permissions

Information about ordering reprints can be found online:

http://nn.neurology.org/misc/addir.xhtml\#reprintsus

Neurol Neuroimmunol Neuroinflamm is an official journal of the American Academy of Neurology.

Published since April 2014, it is an open-access, online-only, continuous publication journal. Copyright

Copyright $\odot 2019$ The Author(s). Published by Wolters Kluwer Health, Inc. on behalf of the American

Academy of Neurology.. All rights reserved. Online ISSN: 2332-7812.

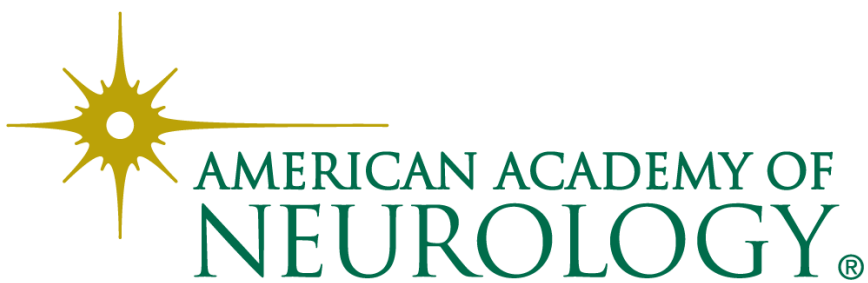

